\title{
A longitudinal study of nest occupancy, trail networks and foraging in a polydomous wood ant population
}

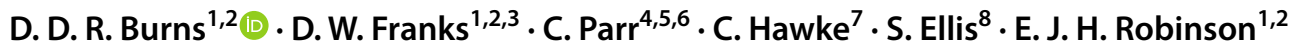

Received: 13 December 2019 / Revised: 13 May 2020 / Accepted: 2 July 2020 / Published online: 11 July 2020

(c) The Author(s) 2020

\begin{abstract}
Most ant colonies live in a single nest (monodomy) or a group of nests (polydomy). However, the length of time for which nests are inhabited varies significantly between different species. Although colonies of some species frequently move nest sites, in others, colonies inhabit the same nest or group of nests for many years. Similarly, in some species foraging and resource-sharing trails are highly dynamic, while in other species trails are used for years. Wood ants are a group of keystone species that inhabit many northern hemisphere woodlands, where they are important predators of invertebrates and indirectly act as herbivores through the farming of aphids. Wood ant colonies exhibit both monodomy and polydomy, and can inhabit nests for many years. Trails in wood ant colonies are also thought to be relatively stable. However, information about colony dynamics is mostly anecdotal as, until now, no longitudinal datasets have been collected. In this study, we collected data from ten polydomous wood ant colonies annually for 8 years and a subset of four colonies 16 times over 2 years. We found that most polydomous wood ant nests are abandoned in the first 2 years after being constructed and are more likely to be abandoned in the latter part of the active season. However, the rate of nest abandonment decreases after 2 years and is lower in larger nests. We also found that wood ant trails are relatively static within an active season and become more static later in the season as trails become established.
\end{abstract}

Keywords Wood ants $\cdot$ Polydomy $\cdot$ Formica lugubris $\cdot$ Longitudinal studies $\cdot$ Nest foundation $\cdot$ Social networks

Electronic supplementary material The online version of this article (https://doi.org/10.1007/s00040-020-00777-2) contains supplementary material, which is available to authorized users.

D. D. R. Burns

db1133@york.ac.uk

1 Department of Biology, University of York, York, UK

2 York Cross-Disciplinary Centre for Systems Analysis, University of York, York, UK

3 Department of Computer Science, University of York, York, UK

4 Department of Earth, Ocean and Ecological Sciences, University of Liverpool, Liverpool, UK

5 Centre for African Ecology, School of Animal, Plant and Environmental Sciences, University of Witwatersrand, Johannesburg, South Africa

6 Department of Zoology and Entomology, University of Pretoria, Pretoria, South Africa

7 National Trust, Heelis, Kemble Drive, Swindon, UK

8 Department of Psychology, University of Exeter, Exeter, UK

\section{Introduction}

Colonies of most ant species inhabit nests that provide shelter from weather, defence from predators and parasites and a place to store resources (Hölldobler and Wilson 1990). However, the duration of nest site occupancy differs dramatically across ant species. In many ant species, colonies move between nesting locations frequently in response to changes in local conditions, availability of food, current nest quality, parasitic load, disease, predation, seasonality, competition and to allow colony growth (McGlynn 2012). For example, colonies of cavity-dwelling Temnothorax spp. ants will move to new nest sites if they are better quality than their current nest site (Dornhaus et al. 2004). In contrast in other species, established colonies may remain in the same nest for decades (Breen 1979; Klimetzek 1981; Ingram et al. 2013; Robinson and Robinson 2008); however, information on nest occupancy in natural populations is limited to a few studies that have monitored individual ant nests for long periods (Klimetzek 1981; Ingram et al. 2013; Robinson and Robinson 2008) and anecdotal information. 
Ant colonies can inhabit either a single nest, termed monodomy, or multiple nests, known as polydomy. In monodomous colonies, a colony occupies a single nest where all resources (e.g. workers, food, brood) are stored. In contrast, in polydomous colonies a colony is divided into several sub-colonies that inhabit different nests (Debout et al. 2007; Robinson 2014). In this study, where it is important to distinguish between the physical nest structure and the population of ants inhabiting the nest structure, we refer to the physical nest structure as the "nest" and the population of ants inhabiting the nest structure as the "sub-colony". Across ant species, both monodomous and polydomous nesting strategies can be associated with either multiple queens (polygyny), or a single queen (monogyny) (Debout et al. 2007; Robinson 2014).

Ant species use a wide range of foraging strategies that are influenced by the characteristics of the resource they are foraging on (Lanan 2014). For example, species that forage on resources that are small and ephemeral in the environment (e.g. small prey) generally forage solitarily, while species that exploit resources that are clumpy and stable (e.g. aphid colonies) generally forage on long-term trail networks (Lanan 2014). In polydomous colonies, there is an extra layer of complexity, because resource distribution influences the ability of different sub-colonies to access food, which in turn influences the topology of internest networks (Ellis and Robinson 2015; Burns et al. 2020). Therefore, it is likely that the spatiotemporal distribution of resources causes different rates of change in the inter-nest networks of different polydomous species.

Wood ants (Formica rufa group) are found in many northern hemisphere woodlands, where they are important predators of many invertebrates and, therefore, are considered to be a keystone species (Robinson et al. 2016). Wood ants are also considered to be ecosystem engineers as they construct large nest mounds of plant material that are kept at high temperatures throughout the year, meaning that they are important sites for decomposition (Frouz et al. 2016). Colonies of wood ants can be either polydomous or monodomous, depending on species and population (Ellis and Robinson 2014). In general, polydomous wood ants form a small number of sub-colonies that inhabit distinct nests and share resources with each other. However, there are some populations of unicolonial wood ants that have formed colonies of several thousand nests (e.g. Higashi and Yamauchi 1979; Marko et al. 2012).

Wood ants forage predominantly on aphid colonies, which they farm for sugary secretions. Consequently, they mainly forage and share food on relatively static foraging and inter-nest trails (Lanan 2014). Recent work identified that wood ant inter-nest and foraging networks can be altered in response to experimental manipulation of resource distribution (Burns et al. 2020). However, due to a lack of longitudinal data, relatively little is known about how these networks change under natural conditions.

Although ants are a commonly used study system, few studies have observed the activities of colonies over a long period. Consequently, there is a lack of basic information regarding colony dynamics. The study of colony dynamics is important for conservation as it provides necessary information on how colonies interact with their habitat and can be used to track population health. Polydomous wood ants are an ideal system for studying nest and trail usage over long timescales as: (1) It is possible to identify nests and estimate their population without disturbance (Chen and Robinson 2013); (2) Most of the foraging occurs on trails so the food available to each sub-colony can be quantified (e.g. Ellis et al. 2014); (3) Trails are above-ground so the destination of trails from each nest is easy to identify and strength of trails can be measured (e.g. Ellis et al. 2014); and (4) Nest and trail use change relatively slowly meaning that it is possible to identify the majority of changes and the order that they happened (e.g. Ellis et al. 2017).

In this study, we present a dataset of ten polydomous Formica lugubris colonies that we observed annually over 8 years. We also present data on a subset of four of those ten colonies that were observed 16 times over a 2 -year period. We investigate the rate at which nests and trails are established and abandoned in natural ant colonies and compare colony behaviour at different times in the active season.

\section{Methods}

\section{Study site}

The population of wood ants (Formica lugubris) used for this study is found at National Trust's Longshaw Estate in the Peak District, UK $\left(53^{\circ} 18^{\prime} 55^{\prime \prime} \mathrm{N}, 1^{\circ} 36^{\prime} 18^{\prime \prime} \mathrm{W}\right)$. The site is ideal for the study of wood ant trail networks as vegetation is relatively sparse, meaning that it is easy to identify trails and quantify trail strength, and ants at the site forage mostly on aphids found in trees, meaning that food sources are easy to identify. Wood ants at the site are predated at a low level by green woodpeckers (Picus viridus) and European badgers (Meles meles), although the frequency of predation events seems to be rare and does not generally result in nest abandonment. The field site has been used for the study of wood ants for many years, including work on nest networks (e.g. Cook et al. 2014; Ellis et al. 2014; Ellis and Robinson 2016).

\section{Mapping}

We collected data only on warm, dry and sunny days, when the colonies are most active (Burns personal observation). To map the colonies, we identified foraging and inter-nest 
trails, which are visible due to short grass at the site. For each trail, we recorded length and strength. We estimated the length of each trail by measuring the distance between the two nests or the nest and food source that the trail connected. We estimated trail strength by measuring the length of the trail it took to find 10 ants, with a minimum detectable strength of 10 ants $/ 4 \mathrm{~m}$ of trail and a maximum detectable strength of 10 ants $/ 10 \mathrm{~mm}$ of trail. There is usually no difference in the strength of the trail depending on how close it is to the mound as trails generally do not split (Burns personal observation). In the rare cases where a trail did split, we always measured the strength after the split. We estimated number of ants active on a trail (trail activity) by multiplying the length and the strength of the trail (Trail length $\times$ ants $\mathrm{m}^{-1}$ ). Because we did not collect directional data, it is not possible to estimate the proportion of active ants on an inter-nest trail that came from each nest. Therefore, for inter-nest trails, we assign half of the ants from a trail to each of the nests connected by it. The proportion of a colony active on trails was estimated through dividing the nest population by the total number of ants active on trails. We recorded new trails as being "added" by a colony when they were detectable using this method and recorded old trails that were no longer detectable using this method as being "removed".

We recorded the size and spatial location of all inhabited nests that were connected through the inter-nest trail network. Measurements of each nest's volume were then used to estimate the population size of the sub-colony inhabiting it, using a formula calibrated previously at this site (Ellis et al. 2014). Finally, we recorded the location and species of trees that were connected to nests by foraging trails. Using the data, we produced network maps of the inter-nest connections and the foraging connections between nests and trees (e.g. Fig. 1). This method of mapping is the same as has previously been used to map this population (e.g. Ellis and Robinson 2015).

We collected network maps for ten colonies annually for 8 years (2012-2019). Colonies were defined as being any group of nests that were connected through inter-nest trails. Nests that were at some point connected to the network but were not connected at a later time point were also considered to be part of the same colony. Although there are over 900 nests at the study site, not all nests are incorporated into large polydomous colonies. For this study, ten of the largest polydomous colonies at the site were selected for observation. At the first time point, colonies occupied a mean of ten nests (range 4-20). Throughout this study, we continued to record maps for each colony annually. In addition, for four of these colonies, we recorded maps every $2-4$ weeks in the active season (roughly April-September) for 2017 and 2018, resulting in eight time points per colony per year. Five of the colonies that are included here were subject to manipulation

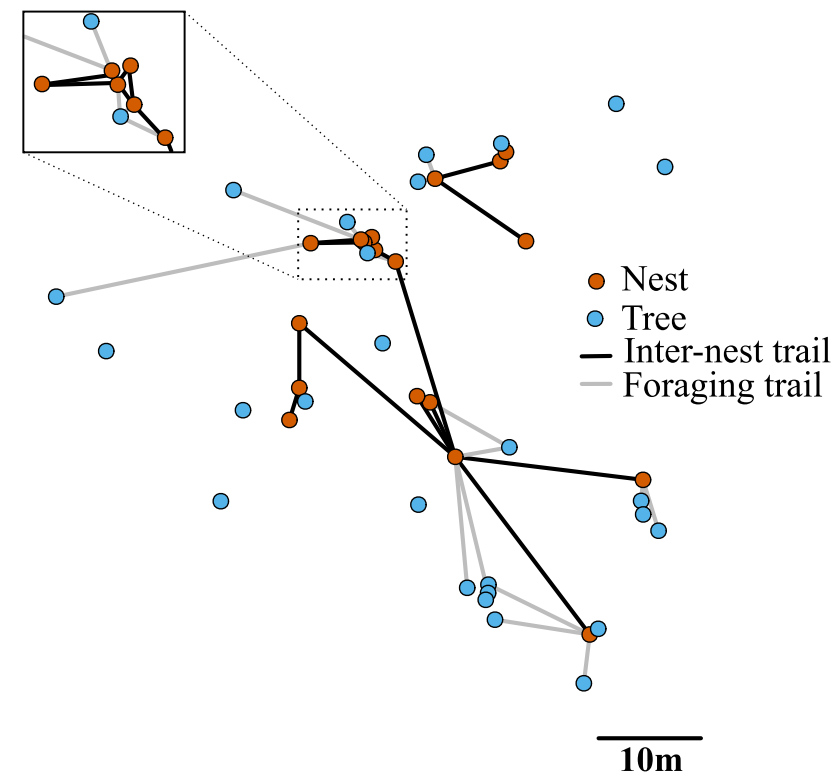

Fig. 1 An example network map. Nodes are positioned relative to their locations in space. Red nodes indicate nests and yellow nodes indicate trees. Each node is labelled with the unique ID of the node. Foraging trails are indicated by grey edges and inter-nest trails are indicated by black edges. Trails are drawn as topological straight lines as the actual shape of each trail was not measured. Trail strength is not illustrated in this diagram. Estimating time of nest foundation and abandonment

of food sources in 2017 as part of an experiment (Burns et al. 2020). However, because we did not find any effect of the experimental manipulation on nest abandonment or foundation (Burns et al. 2020), we have not excluded these colonies from the study of nest inhabitancy. The subset of four colonies that were mapped regularly in 2017 and 2018 were used only as controls for the manipulation experiment and, therefore, were unaffected by manipulation and are used for the study of changes to trail networks. The details of mapping dates for each colony are detailed in Supplementary Appendix 1.

We estimated the foundation and abandonment dates for each nest that was inhabited in any of the timepoints where the full set of colonies were observed. We did not include data from timepoints where only a subset of the colonies was observed in this analysis, because this would have led to differing data quality between colonies. To approximate the date of nest foundation, we use the midpoint between the first timepoint that the nest was observed and the previously recorded timepoint. Similarly, to estimate the date of nest abandonment we use the midpoint between the last timepoint the nest was observed and the next time point. This method can result in nest foundation dates being outside of the active season (i.e. a nest is abandoned or founded after the last timepoint of 1 year and before the first timepoint of the next year). However, this method minimises error 
between our estimations and the likely actual nest foundation and abandonment dates. If a nest was abandoned and then recolonised, we counted the abandonment and recolonisation as founding and abandonment events.

\section{Assignment of nest founders}

We used inter-nest trails and distances to assign the nests inhabited by founding sub-colonies (Ellis et al. 2017). In most cases $(150 / 273,54.9 \%)$, a new nest was connected by a single inter-nest trail which led to an old nest, which we assigned as the founder. If there was more than one inter-nest trail to previously existing nests $(53 / 273,19.4 \%)$, then we assigned the nest with the shortest connection as the founder. Finally, if the new nest was not connected to any old nests $(70 / 273,25.6 \%)$ then we assigned the closest old nest as the founder. If a new nest is only connected to another new nest, we do not consider this to be a potential founding connection because it is not possible to ascertain which nest was founded first.

\section{Assessment of seasonal differences}

We used the subset of four colonies that were measured 16 times over 2 years to assess seasonal differences in foundation, abandonment and activity. We divided the active season into two parts to assess differences between total trail activity in the early part of the active season and total trail activity in the late part of the active season. We considered any timepoint in the first half of the active season (May or June) to be 'early season' and any timepoint in the second half of the active season (July or August) as 'late season'.

\section{Statistical analysis}

We used Linear Mixed Models (LMMs) and Generalised Linear Mixed Models (GLMMs) to test different hypotheses using the data. We used Levene's test to check each model for equal variances. The descriptions and results of each statistical model are detailed in Supplementary Appendix 2.

To describe the distribution of the number of new nests founded by each sub-colony, we tested the observed distribution against a selection of different distributions to identify if there were any distributions that fit the data well. Full results of the model fits are detailed in Supplementary Appendix 3.

All data manipulation and analysis was performed in $\mathrm{R}$ version 3.5.2 (R Core Team 2013), statistical models were fitted using the lme4 package (Bates et al. 2015), distributions were fit using the MASS package (Venables and Ripley 2013), network diagrams were made using igraph (Csardi and Nepusz 2006), and data manipulation and graphs were produced using the Tidyverse suite of packages (Wickham et al. 2019).

\section{Results}

\section{Age structure, survival and nest foundation}

In the dataset of ten colonies that were mapped annually over 8 years, we found that 30 of the 107 (28.04\%) nests occupied at the most recent timepoint (June 2019) were established before the study period began (July 2012). Consequently, although we do not know exactly how long these nests have been inhabited, we do know that they have been continuously inhabited for at least 7 years. Of the remaining 77 nests, $37(48.05 \%)$ were inhabited for less than a year (Fig. 2). Across the years that we observed the colonies, $32.2 \pm 6.8 \%($ mean $\pm \mathrm{SD})$ nests were abandoned per year, on average.

During the first 4 years of the study period, 89 new nests were established in our 10 study colonies. We found that $52(58.4 \%)$ of these nests were inhabited for less than 2 years before being abandoned, while 25 (28.1\%) were inhabited for at least 3 years (Fig. 3).

The number of nests founded by a single sub-colony fits a negative-binomial distribution very closely with a mean of 0.52 and a size of $0.61\left(\chi^{2}=4.24, p=0.64\right.$, full fitting details in Supplementary Appendix 3), with the majority of sub-colonies (105 of $157,66.9 \%$ ) that founded new nests founding a single nest in the season (Fig. 4). We find an extreme outlier of ten new nests founded by a single sub-colony but it is possible that the new nests were not actually newly founded and, instead, may have been part of a separate previously unconnected network. Foundation of new nests during the study period was mostly performed by a minority of sub-colonies, with $33.5 \pm 24.5 \%$ (mean $\pm \mathrm{SD}$ ) of sub-colonies in a colony founding new nests in any given year. Larger nests were more likely to survive than smaller nests (Fig. 5; Table A2.1 in Supplementary Appendix: Model 9; GLMM: $Z=7.33, p<0.001)$ and were also more likely to found another nest (Fig. 5; Table A2.1 in Supplementary Appendix: Model 8; GLMM: $Z=4.94, p<0.001)$.

\section{Seasonal differences in sub-colony activity}

In sub-colonies inhabiting nests from the four colonies that were monitored at high frequency in 2017 and 2018, we did not find any difference in the total strength of foraging (Table A2.1 in Supplementary Appendix: Model 1; LMM: $T=-0.92, p=0.36$ ), inter-nest (Table A2.1 in Supplementary Appendix: Model 2; LMM: $T=1.02, p=0.31$ ) or both foraging and inter-nest (Table A2.1 in Supplementary Appendix: Model 3; LMM: $T=0.17, p=0.86$ ) trails between maps recorded early and those recorded late in the 


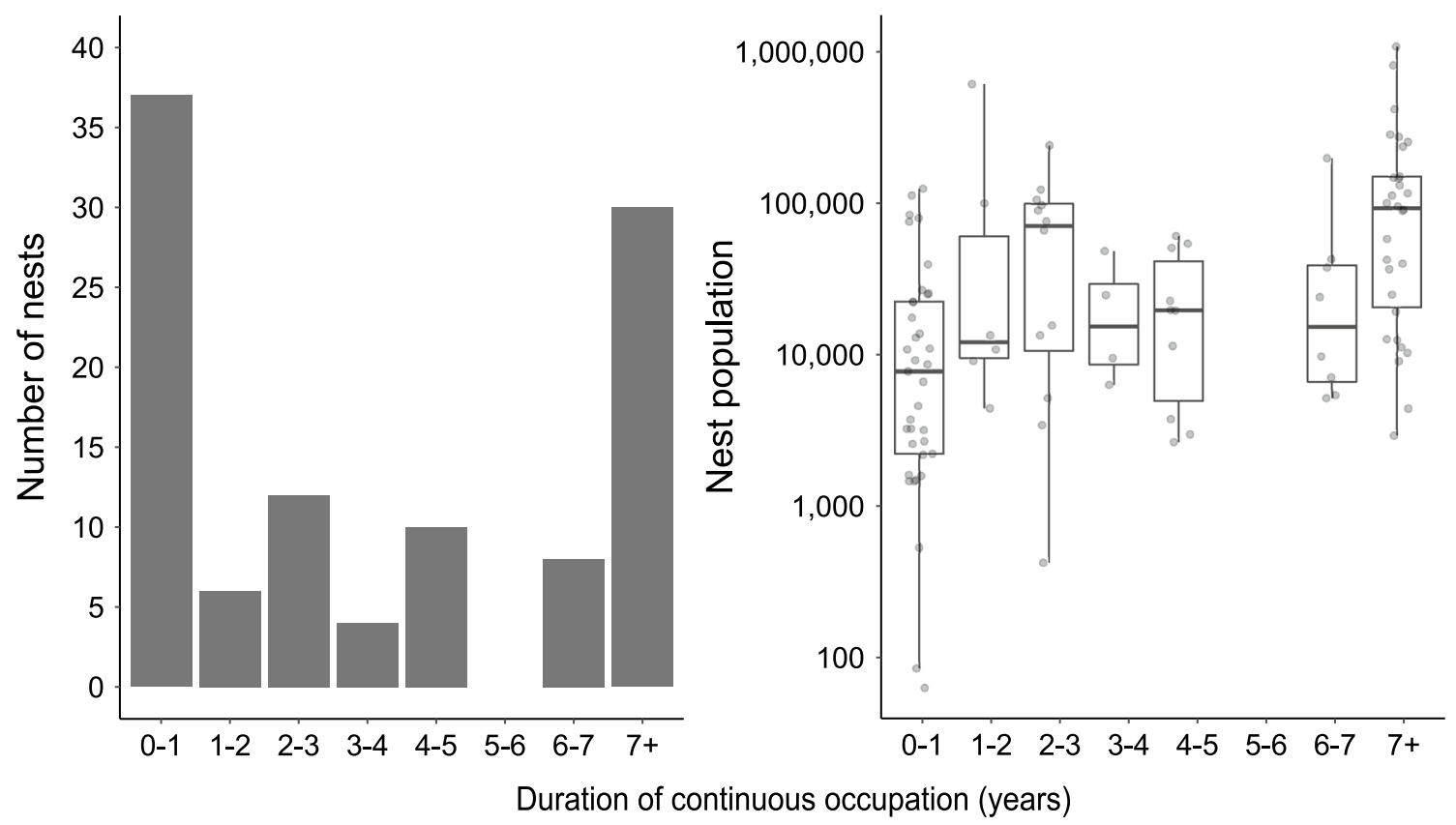

Fig. 2 Distribution of the time that nests that were inhabited at the end of the study (2019) had been continuously inhabited (i.e. age structure of the population of nests) and the size of nests in each group. In the panel on the right, each data point represents a single

data point from an individual nest. For nests inhabited for the duration of the study, only the minimum age is known, indicated as $7+$. Most nests are either abandoned in the first year or inhabited for many years

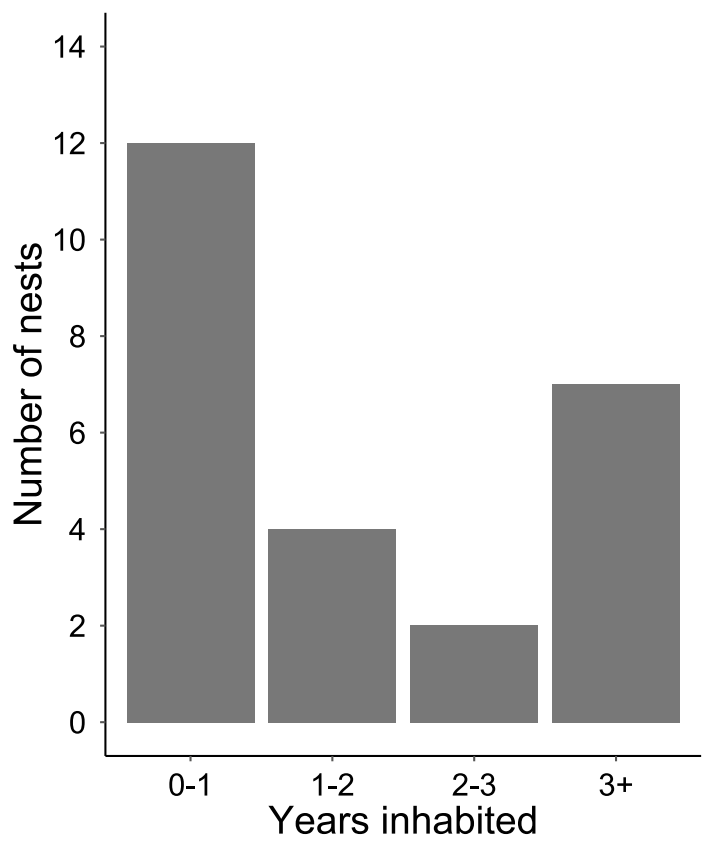

Fig. 3 Distribution of the time that nests founded in the first 4 years of the study was inhabited before being abandoned. Due to continued occupancy of nests at the end of the study period, we only know the minimum occupancy for some nests. Most nests are either abandoned quickly or inhabited for many years

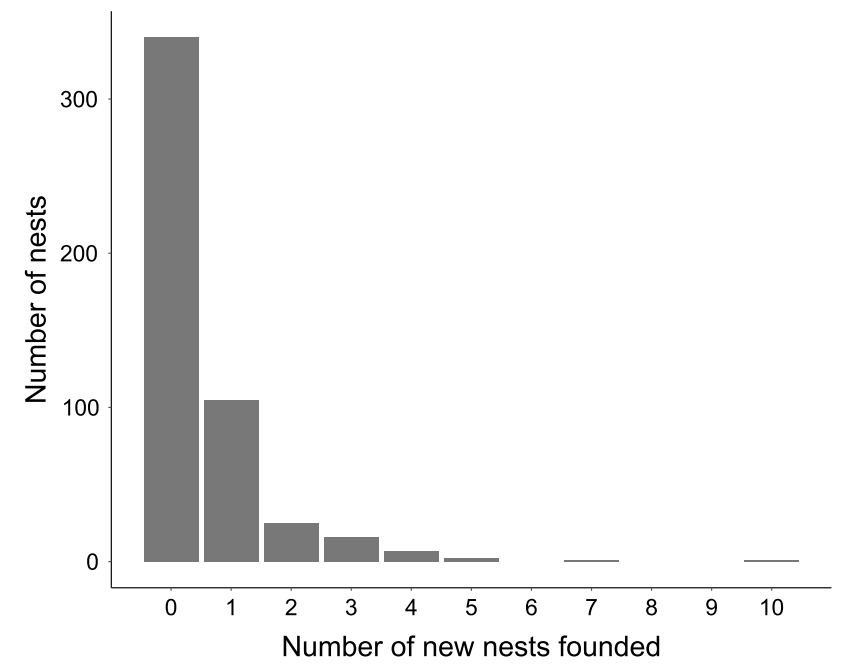

Fig. 4 Distribution of the number of new nests founded by each nest in a season. All data points represent the activity of a single nest in a season. Most nests do not found any other new nests, but those that do generally produce a single new nest

season (Fig. 6). There was also no significant seasonal difference in the rate of nest foundation (Fig. 7a; Table A2.1 in Supplementary Appendix: Model 4; GLMM: $Z=-1.3$, $p=0.20$ ). However, there were more nests per colony abandoned in the late season compared with the early season (Fig. 7b; Table A2.1 in Supplementary Appendix: 


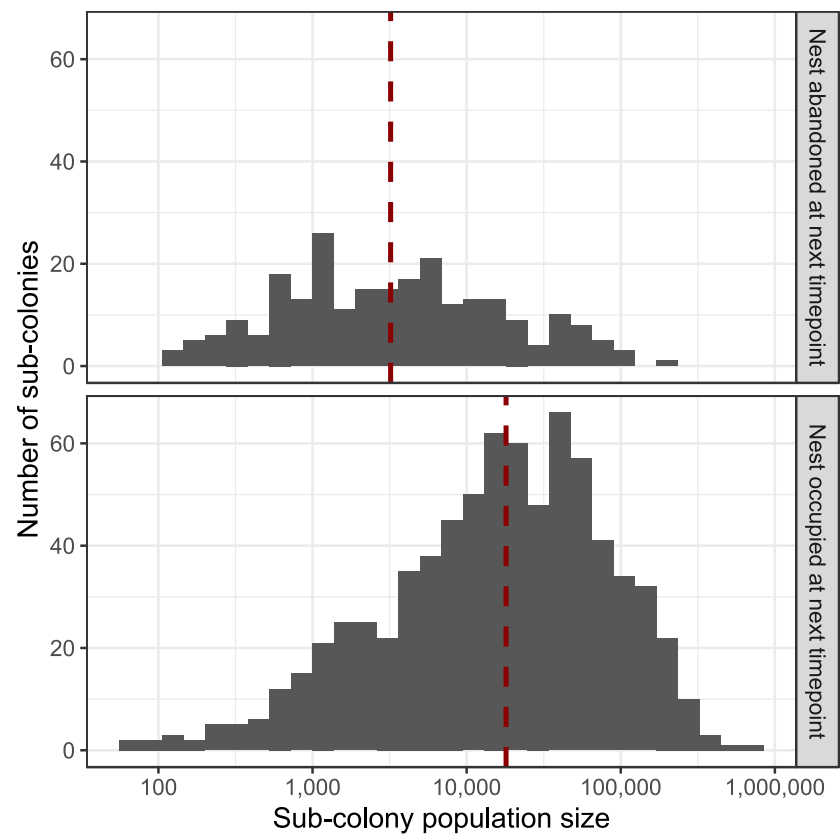

Fig. 5 The distribution of population sizes of sub-colonies in different groups. Red dashed lines indicate median values. The left panel shows the distribution of the population of sub-colonies that were occupied at the next timepoint and those that were not. Sub-colonies that were still occupying their nest at the next timepoint were larger

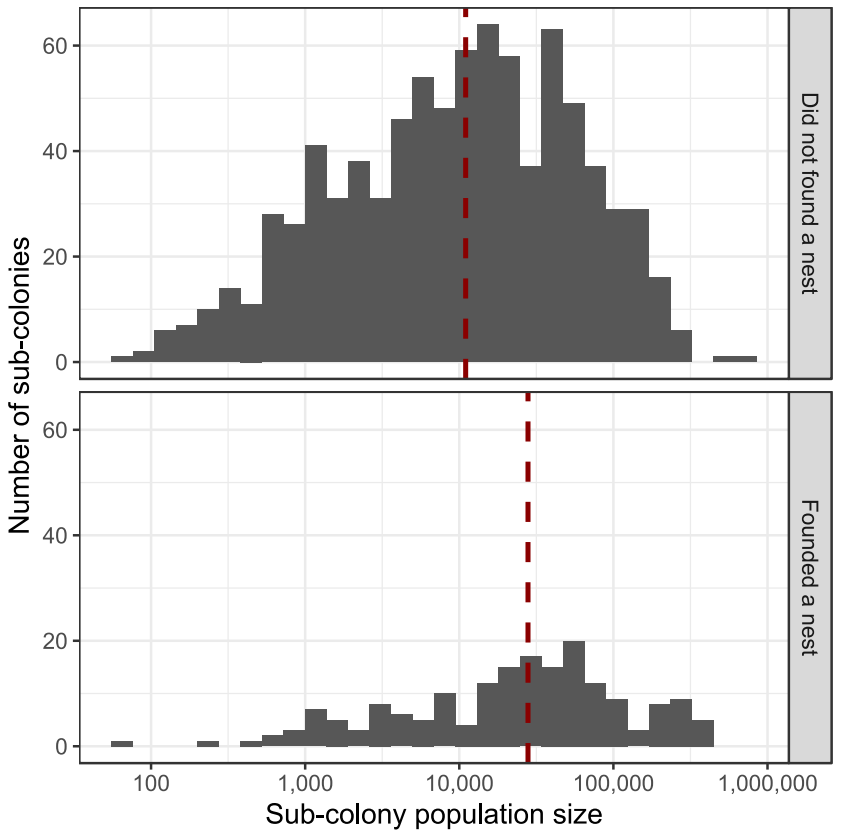

than those that abandoned their nest before the next timepoint. The right panel shows the distribution of the population of sub-colonies that founded a new nest and those that did not. Sub-colonies that founded new nests were larger than those that did not

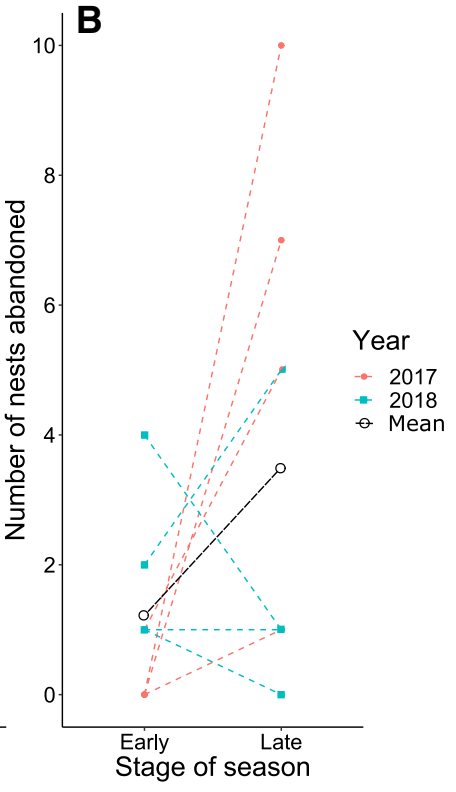

Fig. 7 Seasonal differences in nest foundation (a) and abandonment (b) for nests in four regularly mapped colonies in 2017 and 2018. Each point represents a colony and dotted lines indicate data from the same colony in the same year. Means for each season are represented by open black circles. There is no difference in nest foundation between early and late season, but more nests are abandoned in the latter part of the season 


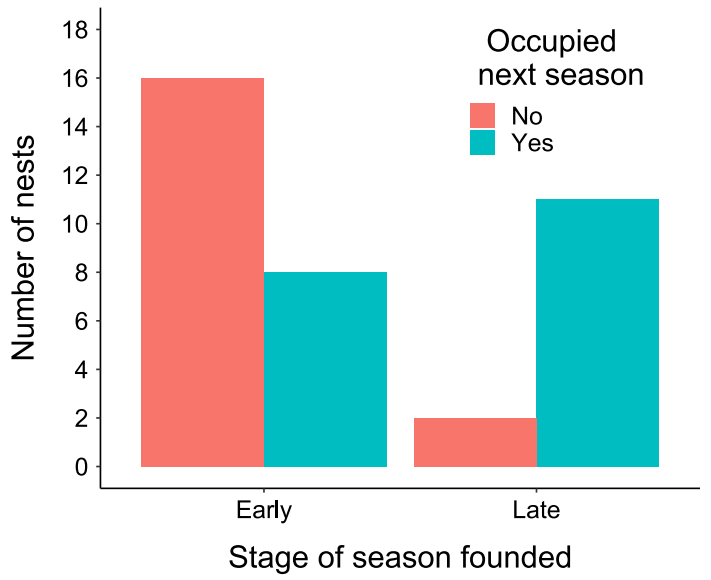

Fig. 8 The number of nests that were occupied the following active season and the part of the season that they were founded in. Nests that were founded in the early stage of the active season were less likely to still be occupied the following season than nests that were founded in the late stage of the active season

of the season were more likely to still be inhabited the following season (Fig. 8; Table A2.1 in Supplementary Appendix: Model 10; GLMM: $Z=2.55, p=0.011$ ). Additionally, the rates at which trails were added (Table A2.1 in Supplementary Appendix: Model 6; GLMM: $Z=-3.94$, $p<0.001$ ) and removed (Table A2.1 in Supplementary Appendix: Model 7; GLMM: $Z=-2.21, p=0.027$ ) were higher in the early season compared to the late season (Fig. 9).

\section{Rate of trail usage and colony change}

In the four colonies that were mapped frequently in 2017 and 2018 (Table A1.1 in Supplementary Appendix), trail usage changed (new trails added, or existing trails removed) at a mean rate of $0.36 \pm 0.33$ (mean $\pm \mathrm{SD}$ ) trails per nest per week. Consequently, the rate of change for trail networks was slow, with $59.8 \%$ of foraging trails and $64.5 \%$ of internest trails that were active at the first timepoint of the season also being active at the last timepoint of the season. Of the nests that were inhabited at the first timepoint of the season, $82.7 \%$ were still inhabited at the last time point of the season.

\section{Discussion}

We found that most nests were inhabited for less than a year before being abandoned. However, the nests that were inhabited for longer than a year grew larger and were often inhabited for more than 3 years, and many of these were still occupied at the end of our sampling period. This finding supports previous evidence showing that newly founded nests in

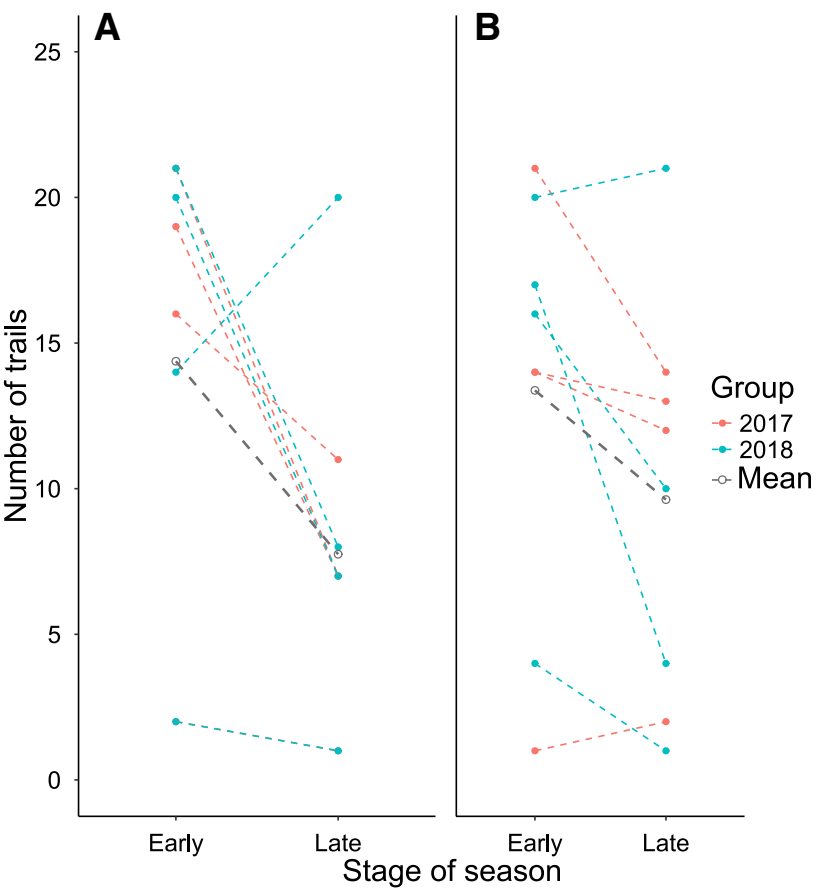

Fig. 9 Number of trails added (a) or removed (b) early and late in the season. Each point within the season stage represents a colony and dotted lines indicate paired data from the same colony in the same year. Means for each season are represented by open black circles. There are more trail additions and trail removals in the early season compared to the late season

polydomous colonies have a much higher rate of abandonment than established nests (Sorvari and Hakkarainen 2007). These findings also support the hypothesis that nest foundation in polydomous colonies is an important way for colonies to optimise the position of their nests (Ellis et al. 2017; Ellis and Robinson 2015). Sub-colonies that build nests in favourable locations begin foraging, grow and inhabit the nest for many years. In contrast, sub-colonies that build nests in unfavourable locations are unable to forage effectively and abandon the nest after a short time (Ellis and Robinson 2015). We also found that nest foundation events are relatively rare, with only around a third of nests in a colony budding a new nest in a given year, and with larger nests being more likely to bud a new nest than smaller nests.

A previous study found that most new polydomous Formica yessensis nests were constructed early in the season and most abandonments occur late in the season (Higashi 1976). Nest foundation early in the season is thought to be important for allowing nests the maximum amount of time to grow and collect resources for the winter months (Higashi 1976; Risch et al. 2016). However, we find a similar number of foundation events occurring in both the early and the late part of the season. Interestingly, our results show that nests that were founded in the late part of the season were more likely to still be inhabited the following season. This may 
be because sub-colonies that separate in the early part of the season have time to move or be absorbed into another sub-colony before the end of the season, while nests founded later in the season have less time to respond to local foraging conditions. This finding contrasts with previous hypotheses that nest foundation occurs in the early part of the season to maximise survival into the next season (Higashi 1976; Risch et al. 2016). In concordance with previous work (Higashi 1976), we found that more nests were abandoned late in the season. This might be because sub-colonies that found nests early in the season move the nest to a more favourable location or move into another existing nest before the season is finished. We also found that larger nests are less likely to be abandoned than smaller nests and more likely to found new nests. This is perhaps unsurprising as larger nests are likely to have become large as a result of being in a good location and are more likely to survive winters due to being larger and, therefore, easier to heat (Frouz et al. 2016).

Previous observations of polydomous wood ants indicate that inter-nest trails are established after foraging trails (Rosengren 1983). In this study, we find that inter-nest and foraging activity are similar in the early and the late season. One likely explanation for this difference is that both inter-nest and foraging trails were established by the time we produced the first maps in May. Interestingly, we find that the rate of change for trails was reduced in the later part of the season with fewer trails being added or removed late in the season compared to early in the season. As the distribution of food in the environment is relatively static, trail networks may become more stable as the network becomes better matched to the resource environment.

In general, we find that foraging and inter-nest networks in the wood ant colonies change at a relatively slow rate, with most trails that are active at the start of a season also being active at the end of the season. This is not surprising as wood ants forage on static resources (Lanan 2014) and the configuration of inter-nest networks is influenced by the configuration of foraging networks (Ellis and Robinson 2016; Burns et al. 2020). It is likely that foraging and inter-nest networks are much more dynamic in polydomous ant species that forage on more transient food sources.

Previous work on another polydomous wood ant species, Formica aquilonia, found annual nest abandonment rates of $<2 \%$ in undisturbed forest interiors, but $>50 \%$ in recently clear-cut areas (Sorvari and Hakkarainen 2007). In this study, we found an annual nest abandonment rate of $32.2 \pm 6.8 \%$ (mean $\pm \mathrm{SD}$ ), which is considerably higher than was found in undisturbed habitat by Sorvari and Hakkarainen (2007), but lower than the abandonment rate that they found in clear-cut areas. One possible reason for this difference is that Formica lugubris is an edge specialist, so the nesting locations available in the habitats where $F$. lugubris is present are much more variable in quality due to resources being sparser. As a result, there may be a higher rate of nest abandonment due to nests being abandoned and rebuilt elsewhere.

It seems likely that rates of nest foundation and abandonment would be quite different in populations that are monodomous or monogynous compared to the polydomous and polygynous species studied here. First, the survival of monogynous colonies is finite due to the dependence on a single queen, while polygynous colonies can, in theory, survive indefinitely. Second, it is possible that there is less nest relocation in monogynous colonies as the cost of losing the queen during moving is higher. Third, in monodomous colonies, nest foundation is riskier than in polydomous colonies, as sub-colonies that fail to establish a nest cannot return to their previous nest. Finally, monodomous colonies are less likely to succeed in founding a new nest as, generally, nests are founded by a single queen, whereas many workers are involved in founding a new polydomous nest. In contrast to this supposition, one previous study on several different, mostly monodomous, wood ant species found that nests were abandoned at a rate of $21-33 \%$ and roughly $31-51 \%$ of nests were involved in nest foundation every year (Klimetzek 1981). This is very similar to what we found in this study and indicates that different nesting strategies may not actually be so important in determining the duration of nest occupancy and rates of nest foundation. However, a more direct comparison of different strategies in similar locations would be necessary to test this hypothesis more conclusively.

Although we found that some nests were inhabited for a long time, we also found that many of the nests were inhabited very briefly. This may be due to a high level of resource utilisation, where new nests cannot grow due to a lack of available resources. If this is the case, when older nests are abandoned they may be replaced quickly by new nests that are able to take over food sources. However, there is little information available on the factors that cause nest abandonment in new nests. Future work to establish what factors are important in determining the continued inhabitation of new nests would likely provide useful information regarding the vulnerability of polydomous wood ants populations and guide conservation efforts.

In this study, we mapped colonies annually for 8 years, but many nests were present throughout, meaning we have no data on their foundation or abandonment. Continued monitoring of this and other comparable populations would increase the quality of the available data and help to further develop an understanding of how ant colonies use nests and how their activities change over time. Future work in this area would likely provide useful insights into ant ecology and behaviour. For example, it would be interesting to compare what we have found in polydomous wood ants to similar data for monodomous wood ants and polydomous ants of different species, particularly those that forage on resources 
with very different characteristics. The evolutionary and ecological drivers of polydomy and monodomy are still not clear (Burns et al. 2019; Ellis and Robinson 2014; Robinson 2014). Consequently, comparative work on closely related species may help improve understanding of the evolution of colony organisation and of cooperation more generally.

Acknowledgements We would like to thank Phillip Buckham-Bonnett, Eleanor Drinkwater, Calvin Dytham, Megan Holgate, Valentin Lecheval, Josie Monaghan, Jon Pitchford and Joshua Sammy for their helpful feedback on the manuscript at different points. We would also like to thank the National Trust staff at Longshaw Estate for their help with logistics at the site. The project was funded by the NERC ACCE DTP (Grant code: NE/L002450/1).

Open Access This article is licensed under a Creative Commons Attribution 4.0 International License, which permits use, sharing, adaptation, distribution and reproduction in any medium or format, as long as you give appropriate credit to the original author(s) and the source, provide a link to the Creative Commons licence, and indicate if changes were made. The images or other third party material in this article are included in the article's Creative Commons licence, unless indicated otherwise in a credit line to the material. If material is not included in the article's Creative Commons licence and your intended use is not permitted by statutory regulation or exceeds the permitted use, you will need to obtain permission directly from the copyright holder. To view a copy of this licence, visit http://creativecommons.org/licenses/by/4.0/.

\section{References}

Bates D, Mächler M, Bolker B, Walker S (2015) Fitting linear mixedeffects models using lme4. J Stat Softw 67:1-48

Breen J (1979) Nest sites of Formicalugubris (Hymenoptera, Formicidae) in Irish plantation woods. J Life Sci R Dublin Soc 1:13-32

Burns DDR, Pitchford JW, Parr CL, Franks DW, Robinson EJH (2019) The costs and benefits of decentralization and centralization of ant colonies. Behav Ecol 30(6):1700-1706

Burns DDR, Franks DW, Parr CL, Robinson EJH (2020) Ant colony nest networks adapt to resource disruption. J Anim Ecol. https:// doi.org/10.1111/1365-2656.13198

Chen Y-H, Robinson EJH (2013) A comparison of mark-releaserecapture methods for estimating colony size in the wood ant Formica lugubris. Insectes Soc 60:351-359

Cook Z, Franks DW, Robinson EJH (2014) Efficiency and robustness of ant colony transportation networks. Behav Ecol Sociobiol 68:509-517

Csardi G, Nepusz T (2006) The igraph software package for complex network research. Int J Complex Syst 1695:1-9

Debout G, Schatz B, Elias M, Mckey D (2007) Polydomy in ants: what we know, what we think we know, and what remains to be done. Biol J Linn Soc 90:319-348

Dornhaus A, Franks NR, Hawkins R, Shere H (2004) Ants move to improve: colonies of Leptothoraxalbipennis emigrate whenever they find a superior nest site. Anim Behav 67:959-963

Ellis S, Robinson EJH (2014) Polydomy in red wood ants. Insectes Soc 61:111-122

Ellis S, Robinson EJH (2015) The role of non-foraging nests in polydomous wood ant colonies. PLoS ONE 10:e0138321
Ellis S, Robinson EJH (2016) Internest food sharing within wood ant colonies: resource redistribution behavior in a complex system. Behav Ecol 27:660-668

Ellis S, Franks DW, Robinson EJH (2014) Resource redistribution in polydomous ant nest networks: local or global? Behav Ecol 25:1183-1191

Ellis S, Franks DW, Robinson EJH (2017) Ecological consequences of colony structure in dynamic ant nest networks. Ecol Evol $7: 1170-1180$

Frouz J, Jílková V, Sorvari J (2016) Contribution of wood ants to nutrient cycling and ecosystem function. In: Stockan JA, Robinson EJH (eds) Wood ant ecology and conservation. Cambridge University Press, Cambridge, pp 207-220

Higashi S (1976) Nest Proliferation by Budding and Nest Growth Pattern in Formica (Formica) yessensis in Ishikari Shore. J Fac Sci Hokkaido Univ Ser VI Zool 20:359-389

Higashi S, Yamauchi K (1979) Influence of a supercolonial ant Formica (Formica) Yessensis Forel on the distribution of other ants in Ishikari coast. Jpn J Ecol 29(3):257-264

Hölldobler B, Wilson EO (1990) The ants. Harvard University Press, Cambridge

Ingram KK, Pilko A, Heer J, Gordon DM (2013) Colony life history and lifetime reproductive success of red harvester ant colonies. J Anim Ecol 82:540-550

Klimetzek D (1981) Population studies on hill building wood-ants of the Formica rufa-group. Oecologia 48:418-421

Lanan M (2014) Spatiotemporal resource distribution and foraging strategies of ants (Hymenoptera: Formicidae). Myrmecol News/ Osterreichische Gesellschaft fur Entomofaunistik 20:53

Marko B, Czekes Z, Erós K, Csata E, Szasz-Len A-M (2012) The largest polydomous system of Formica ants (Hymenoptera: Formicidae) in Europe discovered thus far in Romania. North West J Zool 8(2):287-291

McGlynn TP (2012) The ecology of nest movement in social insects. Annu Rev Entomol 57:291-308

R Core Team (2013) R: a language and environment for statistical computing

Risch A, Ellis S, Wiswell H (2016) Where and why? Wood ant population ecology. In: Stockan JA, Robinson EJH (eds) Wood ant ecology and conservation. Cambridge University Press, Cambridge, pp 81-105

Robinson EJH (2014) Polydomy: the organisation and adaptive function of complex nest systems in ants. Curr Opin Insect Sci 5:37-43

Robinson NA, Robinson EJH (2008) The population of the red wood ant Formica rufa L. (Hymenoptera: Formicidae) at Gait Barrows National Nature Reserve, Lancashire, England over the 20 year period 1986-2006. Br J Entomol Nat Hist 21:225-241

Robinson EJH, Stockan JA, Iason GR (2016) Wood ants and their interaction with other organisms. In: Stockan JA, Robinson EJH (eds) Wood ant ecology and conservation. Cambridge University Press, Cambridge, pp 177-206

Rosengren R (1983) The evolution of polygyny and polydomy in mound-building Formica ants. Acta Entomol Fenn 42:65-77

Sorvari J, Hakkarainen H (2007) Wood ants are wood ants: deforestation causes population declines in the polydomous wood ant Formica aquilonia. Ecol Entomol 32:707-711

Venables WN, Ripley BD (2013) Modern applied statistics with S-PLUS. Springer Science and Business Media, New York

Wickham H et al (2019) Welcome to the Tidyverse. J Open Source Softw 4:1686 